\title{
1. Fresh fruit exports from mainland Southeast Asian countries to China: background context and key questions for research and policy Bill Pritchard
}

\section{INTRODUCTION}

In a relatively rapid space of time, many rural regions in mainland Southeast Asia have become key suppliers of fresh fruit to China. Demand for fresh fruit in China has boomed, such that by 2017 the country had become the world's third largest importer of fresh fruits. ${ }^{1}$ This demand has comprised an increasingly wide diversity of temperate and tropical fruits originating from an increasingly wide set of source countries. However, a crucially important component of this trade has involved the cultivation of tropical fruits for the Chinese market in four mainland Southeast Asian countries - Thailand, Vietnam, Myanmar and Laos. The aim of this introductory chapter to this book is to set out the dimensions of this trade and propose a framework to understand its key characteristics.

This task is motivated by the fact that this topic is under-researched. To date, the entry of Chinese demand as a driver of change in Southeast Asian fresh fruit industries has not been investigated in any significant depth. It can be hypothesised that this research lacuna exists because these developments have been accompanied by substantially differing statistical accounts of the significance of this trade, and key actors have not sought to attract publicity to their efforts. Key sites of fresh fruit production are often in border locations distant from large cities, and for some parts of this trade, exporting occurs through informal or local channels. Hence, the emergence of large Southeast Asian fresh fruit production complexes, oriented to Chinese exports, has happened with little public discussion or systematic research.

It is timely to ask serious questions about this under-researched phenomenon. The creation of a series of China-oriented fresh fruit export complexes in mainland Southeast Asia has important rural development implications. What 
does it mean for strategic agricultural production sites in mainland Southeast Asia as they turn towards China, and their internal dynamics are increasingly inter-meshed with heightened investment and activity from Chinese business interests? How do these developments alter the distribution of economic costs and benefits between industry players, the ways in which production sites are embedded within their constituent regional and national economies, and the longer-term effects on the natural environment?

In this chapter we pursue the aspiration to find answers to these questions. Drawing on information presented in the following eight chapters of this book, and wider research literatures on this issue, a series of specific research problems are posed:

1. What is known currently about the size and characteristics of the trade of fresh fruit from mainland Southeast Asia to China, and what does this imply for methodologies to generate further knowledge about this issue?

2. What insights do existing theory and evidence from other parts of the world suggest in terms of understanding how export-oriented fresh fruit sectors are organised?

3. What are the distinctive characteristics in how fresh fruit sectors in mainland Southeast Asia are organised, and how do these differ from patterns found elsewhere?

\section{PLACING SOUTHEAST ASIA AND CHINA IN GLOBAL TRENDS OF THE TROPICAL FRESH FRUIT TRADE}

The starting point for this study is to understand how the trade in fresh fruit from mainland Southeast countries fits within global-scale patterns. As indicated above, this will enable this chapter to establish the extent of current knowledge about the sector, and consequently identify methodological strategies for addressing resultant knowledge gaps.

Our starting point is to refer to the UN Comtrade database. Fresh fruit is defined as codes 0803 to 0810 inclusive in the Harmonized Commodity Description and Coding System (HS) database. This, however, contains a very broad range of fresh fruit, many of which are not grown in Southeast Asia. Hence, to tailor our analysis to the problem at hand, we will focus on a sub-collection of fresh fruit associated with tropical countries. This sub-collection comprises nine categories of fruit as follows:

- Coconuts in the inner shell (080112);

- Banana (0803);

- Pineapples (080430);

- Guavas, mangoes and mangosteens (080450); 
- Watermelons (080711);

- Melons (other than watermelons) (080719);

- Papayas (papaws) (080720);

- Durian (081060);

- Fresh tamarinds, cashew apples, jackfruit, lychees, sapodillo plums, passion fruit, carambola, pitahaya and other edible fruit (081090)

By country, we focus on the four mainland Southeast Asian countries that are neighbours or near neighbours to China: Vietnam, Laos, Thailand and Myanmar. Comtrade data for these countries and commodities were extracted for the years 2012-2018. In the discussion that follows, reference to 'exports' is defined as exports minus any re-exports (that is, imports that are then exported). This ensures that our discussion on exports focuses on production from each country that was sold across an international border, as opposed to trans-shipped products. However, as discussed below, although this technique should theoretically remove such double counting, this is not necessarily the case in practice, due to inconsistences in data quality and reliability in the Comtrade database.

Table 1.1 Total global exports of tropical fresh fruits to all international markets (USD, mil.)

\begin{tabular}{lllllllll}
\hline Fruit category & HS code & 2012 & 2013 & 2014 & 2015 & 2016 & 2017 & 2018 \\
\hline Bananas & HS0803 & 8,558 & 9,649 & 10,907 & 9,652 & 10,760 & 11,978 & 11,086 \\
Coconuts & HS080112 & 17 & 42 & 82 & 86 & 105 & 175 & 149 \\
Pineapples & HS080430 & 1,673 & 1,733 & 1,797 & 1,581 & 1,923 & 2,044 & 2,003 \\
Guava, mango etc. & HS080450 & 1,591 & 1,886 & 2,098 & 2,029 & 2,362 & 2,914 & 2,965 \\
Watermelons & HS080711 & 1,103 & 1,456 & 1,524 & 1,029 & 1,652 & 1,694 & 1,827 \\
Melons other & HS080719 & 1,407 & 1,503 & 1,645 & 1,240 & 1,648 & 1,647 & 1,416 \\
Durian & HS081060 & 343 & 415 & 650 & 749 & 1,004 & 1,272 & 1,594 \\
Tamarinds and & HS081090 & 2,033 & 2,035 & 2,102 & 2,362 & 3,071 & 3,835 & 3,924 \\
others & & & & & & & & 274 \\
Papaya & HS080720 & 210 & 230 & 255 & 258 & 270 & 274 \\
All of above & & 16,935 & 18,950 & 21,060 & 18,986 & 22,795 & 25,833 & 25,210 \\
\hline
\end{tabular}

Source: UN Comtrade.

From 2012 to 2018, Comtrade records that total global exports of these fresh fruits increased by 49 per cent, from US\$16.9 billion to US $\$ 25.2$ billion (Table 1.1). While banana remains the top tropical fruit item in the global trade, other crops such as coconut and durian exhibit high growth in this period. The four 
mainland Southeast Asian nations (Thailand, Vietnam, Laos and Myanmar) were major contributors to the growth in tropical fruit trade, with the total export value of these products increasing from US\$1.13 billion to $\$ 4.78$ billion in this same period. As a result, these four nations have become a more important global source for these products. Whereas in 2012 these four nations were the origins of 6.7 per cent of exports of these fruits, by 2018 their share had increased to 19.0 per cent (Table 1.2). In particular, the export share of these four nations in the global trade of coconut was 44.6 per cent, 76.4 per cent for durian and 56.8 per cent for tamarinds and other fruits in 2018.

Table 1.2 Thailand, Vietnam, Laos, Myanmar exports as a proportion of global exports of tropical fresh fruit

\begin{tabular}{llllllll}
\hline Fruit category & 2012 & 2013 & 2014 & 2015 & 2016 & 2017 & 2018 \\
\hline Bananas & $0.3 \%$ & $0.8 \%$ & $0.6 \%$ & $1.1 \%$ & $2.8 \%$ & $2.7 \%$ & $3.4 \%$ \\
Coconuts & $20.6 \%$ & $19.4 \%$ & $13.0 \%$ & $4.0 \%$ & $11.0 \%$ & $15.2 \%$ & $44.6 \%$ \\
Pineapples & $0.2 \%$ & $0.1 \%$ & $0.2 \%$ & $0.2 \%$ & $0.1 \%$ & $0.3 \%$ & $0.6 \%$ \\
Guava, mango etc. & $8.7 \%$ & $13.7 \%$ & $14.6 \%$ & $13.1 \%$ & $13.3 \%$ & $22.3 \%$ & $22.7 \%$ \\
Watermelons & $1.0 \%$ & $2.8 \%$ & $4.9 \%$ & $8.3 \%$ & $11.3 \%$ & $10.4 \%$ & $9.6 \%$ \\
Melons other & $0.0 \%$ & $0.5 \%$ & $1.8 \%$ & $1.2 \%$ & $1.3 \%$ & $1.7 \%$ & $2.0 \%$ \\
Durian & $58.6 \%$ & $58.7 \%$ & $59.9 \%$ & $56.3 \%$ & $60.5 \%$ & $75.4 \%$ & $76.4 \%$ \\
Tamarinds and others & $36.8 \%$ & $29.8 \%$ & $30.9 \%$ & $39.2 \%$ & $51.1 \%$ & $57.9 \%$ & $56.8 \%$ \\
Papaya & $0.6 \%$ & $0.6 \%$ & $0.5 \%$ & $0.6 \%$ & $0.4 \%$ & $1.6 \%$ & $0.8 \%$ \\
All of above & $6.7 \%$ & $6.6 \%$ & $7.3 \%$ & $9.6 \%$ & $13.2 \%$ & $17.0 \%$ & $19.0 \%$ \\
\hline
\end{tabular}

Source: UN Comtrade.

Table 1.3 Proportion of global imports destined for China, Hong Kong and Macau

\begin{tabular}{lllllll}
\hline & 2012 & 2013 & 2014 & 2015 & 2016 & 2017 \\
\hline Bananas & $3.2 \%$ & $2.7 \%$ & $5.8 \%$ & $6.0 \%$ & $4.5 \%$ & $4.2 \%$ \\
Coconuts & $87.4 \%$ & $83.3 \%$ & $85.3 \%$ & $86.0 \%$ & $85.0 \%$ & $87.0 \%$ \\
Pineapples & $1.4 \%$ & $2.1 \%$ & $2.7 \%$ & $4.8 \%$ & $5.0 \%$ & $6.1 \%$ \\
Guava, mango etc. & $13.3 \%$ & $13.3 \%$ & $9.3 \%$ & $12.8 \%$ & $8.1 \%$ & $8.0 \%$ \\
Watermelons & $6.6 \%$ & $5.1 \%$ & $2.5 \%$ & $3.8 \%$ & $3.1 \%$ & $3.1 \%$ \\
Melons other & $0.7 \%$ & $0.6 \%$ & $0.8 \%$ & $0.8 \%$ & $0.8 \%$ & $1.0 \%$ \\
Durian & $85.4 \%$ & $92.6 \%$ & $92.4 \%$ & $89.6 \%$ & $85.8 \%$ & $75.7 \%$ \\
Tamarinds and others & $3.4 \%$ & $3.6 \%$ & $3.6 \%$ & $4.3 \%$ & $3.0 \%$ & $3.5 \%$ \\
Papaya & $2.1 \%$ & $2.2 \%$ & $2.3 \%$ & $2.1 \%$ & $2.1 \%$ & $2.0 \%$ \\
All of above & $9.3 \%$ & $9.4 \%$ & $10.9 \%$ & $12.6 \%$ & $10.2 \%$ & $11.1 \%$ \\
\hline
\end{tabular}

Source: UN Comtrade. 
China is a major global importer of tropical fresh fruit, although the recorded rate of import growth stagnated from 2016 (Table 1.3). For these nine product groups in total, the Chinese market modestly increased in importance as an export destination over the period, from 9.3 per cent to 11.1 per cent of global exports.

Although these Comtrade data point to overall trends that appear to be consistent with expectations, closer inspection reveals inconsistencies and, as such, they need to be interpreted with caution. Extracting specific information about the export trade of these products to China from our four mainland Southeast Asian countries of interest (Thailand, Laos, Vietnam and Myanmar) is beset by problems of data unavailability and doubts about reliability in the Comtrade database. This is illustrated in Figure 1.1, which shows the same trade flows as recorded by, respectively, importer (China) and exporter (Thailand, Myanmar, Laos and Vietnam) countries. For all years except 2017, Chinese import data routinely estimated that the value of tropical fresh fruits trade from these four countries was much greater than that recorded by those countries themselves. We now delve into this issue in greater depth.

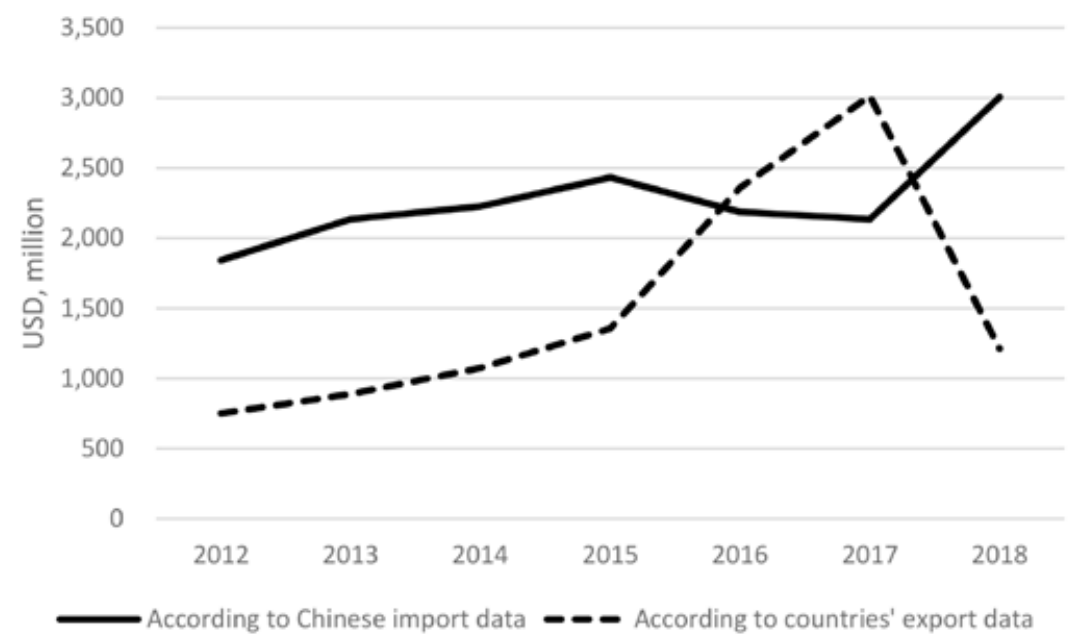

Source: UN Comtrade.

Figure 1.1 The total value of tropical fresh fruits exported from Thailand, Vietnam, Myanmar and Laos, as recorded by

Chinese import data, and exporter countries 
Inconsistencies within Comtrade data can be hypothesised as deriving from several potential sources. Chinese import data is sourced from the official statistics of the Chinese customs service. Export data from the four countries of interest here are derived from a range of sources, sometimes including datasets compiled and collected by industry associations. Estimations of the monetary value of products can differ between these sources. Likewise, measurements of trade volumes can differ, either because of administrative issues or by deliberate design. At border crossings, trade and customs bureaucrats may have incentives to over- or under-measure official trade volumes, in order to adjust duties or fees that are payable. Additionally, not all of the border trade between these four mainland Southeast countries and China flows through official border crossings, creating a further set of problems for measurement. Trade that flows through local crossings may be measured by the exporting country (if it is included in statistics held by industry associations) but not be recognised by the importing country.

These problems of data accuracy are emblematic of the oft-rudimentary status of the apparatus for statistical data collection at border crossings. Although some trade occurs by air or sea, land transportation plays a crucial role in this trade. At land border crossings, the written rules of trade are augmented by a widely acknowledged black market trade not appearing on customs registers. These arrangements reduce the overall traceability of product flows within value chains, giving greater scope to the potential for the mis-certification of product origins, quality characteristics etc., either accidentally or deliberately.

Taken together, these issues pose major implications for research methodology. While the analysis of official trade data, via Comtrade, provides an indicative overview of the size and shape of this trade, it cannot be relied upon to provide a coherent and comprehensive picture of this trade. Hence, in contrast to some studies that use this dataset extensively to analyse the agri-food relationship between Southeast Asia and China, ${ }^{2}$ this chapter argues that real insight into this trade needs to be generated from grounded methodological approaches that assess sites of production by way of surveys, observation and qualitative interviews. These approaches provide a basis for the collection of evidence about how, and in what circumstances, fresh fruit production systems in mainland Southeast Asia are being reoriented and reconfigured to fit within the requirements of servicing the Chinese market. To contextualise the analysis of insights from those methodologies, we firstly assess how existing theory and evidence from the fresh fruit trade in other parts of the world may inform our analysis. 


\section{HOW IS THE TROPICAL FRESH FRUIT ORGANISED? INSIGHTS FROM EXISTING SCHOLARSHIP}

Existing research provides conceptual and empirical insights that can provide a framework for interpreting the diverse and multiple aspects of the fresh fruit trade from Southeast Asia to China. Conceptually, existing research provides a set of terminology that explains key processes in the coordination of fresh fruit production and consumer markets. Empirically, existing research suggests the key features in how fresh fruit in other settings is organised. In this section, we firstly outline the key conceptual framework that we will use hereafter, and then turn to the applications of this framework to case studies of the fresh fruit trade outside of Southeast Asia and China.

There is a huge volume of existing research into the coordination of production systems. Because these issues have been deliberated upon by a diverse array of researchers originating from different home academic disciplines, the terminology and orientation of these approaches vary considerably. In order to maintain consistency in the conceptual approach of this chapter, we will adhere to the framework known as Global Production Networks (GPNs). We do this because this approach emphasises two key elements that are integral to our examination of the Southeast Asia-China fresh fruit trade. First, it gives central attention to the modes of coordination and power relations that are implicit in the connection of sites of production with sites of consumption. Second, it questions the logic of how sites of production are embedded within their regional contexts and thereby 'coupled' into networks for the sale and distribution of their outputs.

Applying this framework to examine the fresh fruit trade form South East Asia to China reveals diverse lead firm arrangements. As discussed below, the organisation of this trade occurs through the corporate integration of logistics, wholesaling and distribution activities, mainly via Chinese-owned entities.

The GPN approach emerged from the work of the 'Manchester school' of economic geographers in the early years of the 2000s. ${ }^{3}$ It was advocated as superior to existing frameworks for analysing the coordination of production and consumption because (1) it conceived the coordination of economic actors within a network (not chain) metaphor, and hence allowed for a more expansive interpretation of the complexity of 'how things come together' to create economic value, and (2) it understood the creation of value as a relational process, involving the mobilisation of regional assets such as labour forces, physical assets and institutional environments. Thus, it was keenly attuned to the importance of geographical differences in explaining why globally mobile capital created particular spatial patterns of growth and neglect. 
GPNs are therefore economic networks constituted through attachments (such as investment, product sourcing, etc.) to geographical sites of value-addition. These networks are conceived as being coordinated by one or more 'lead firms'. ${ }^{4}$ These firms are entities with the market power to organise upstream or downstream economic activities through strategies of purchasing, sub-contracting, intellectual property management, etc.

Lead firms, however, cannot operate in a vacuum. In making decisions about such matters as investment and purchasing, they engage with and navigate through a world riven by diverse spatial attributes. These attributes include differences in relative costs of factors of production (the cost of labour, the cost of land, etc.), differences in political jurisdictions (trade rules, foreign investment rules, etc.), and differences in business cultures and state-business relations. Within the GPN approach, the combination of these attributes relative to specific economic opportunities for lead firms is called 'regional assets'. The process of engaging regional assets with lead firm aspirations is called 'strategic coupling'. According to the GPN approach (and especially the recent theoretical variant known as 'GPN 2.0' $)^{5}$, in a globalised world regional economic growth happens when regional assets are mobilised by strategic coupling and incorporated into GPNs. ${ }^{6}$ Within the GPN approach, three dominant modes of strategic coupling are identified:

- Indigenous coupling: where regions with creative, innovative or high-value local economies expand their value-capture opportunities onto a global stage by engagement with lead firms, for example industrial or creative clusters;

- Functional coupling: where an established arrangement of regional assets, for example a science or agri-industrial park, is connected to lead firm; and

- Structural coupling: where lead firms enter a region to take advantage of fixed assets and these seek to extract value, for example in mining regions.

We now examine how these broad contours of the GPN approach have been applied in research on export-oriented fresh fruit industries. Our analysis is trained on two core questions: (1) what are the main types of lead firm in the fresh fruit industry and how do they seek to coordinate upstream and downstream relations? And (2) what are the varied modes of strategic coupling that connect the regional assets of fruit-production sites to international markets?

Focusing firstly on the issues of lead firm coordination, a defining contextual factor is the fact that tropical fresh fruits tend to be highly perishable, and hence require supportive logistic arrangements to ensure they can arrive at sites of consumption still fresh. Although the shelf-life of fresh fruit can be extended through cooling and chemical applications, this fact nevertheless remains centrally important for the organisational arrangements governing 
this sector, because it has placed key powers and strategic importance on the packing, transport and distribution intermediaries. These entities possess functions including the collection of fruit from upstream producers, aggregate and sort them, prepare them for packaging, and arrange transport to end-country markets.

The evolution of firms with key capabilities in these areas has been documented extensively since the 1990s, when the fresh fruit exports from tropical countries to northern markets in Europe and North America grew rapidly. ${ }^{7}$ Three supportive factors encouraged a boom in fresh fruit exports at this time: agricultural liberalisation in many countries of the global South, which freed farmers to grow high-value productions for profit ${ }^{8}$; harmonisation of sanitary regulations under the aegis of the World Trade Organisation (WTO) and Codex Alimentarius, which reduced non-tariff restrictions to trade; ${ }^{9}$ and rapid reductions to the costs of air-freight, which made the cross-continental export of tropical fresh fruits increasingly commercially viable. ${ }^{10}$

Crucially for the tropical fruits export trade, these developments occurred contemporaneously with significant consolidation and internationalisation of supermarket retailing in the global North. Prior to the emergence of supermarkets with global reach in procurement, the distribution of tropical fresh fruits occurred pre-eminently through wholesale channels. International trading and transport firms would deliver fruits into consuming countries via national wholesale markets, which operated as sites for spot price transactions. The rise of international supermarkets prompted two sets of transformations to these arrangements. First, it encouraged substantial investment and modernisation in wholesale markets associated with efficiencies in logistics and product tracking. The increasing trend for traceability (for example, the preparation and barcoding of product at sites of production, prior to air- land- or sea-freight $)^{11}$ created transactional opportunities outside of wholesale channels. As a result, the role of these places as sites for spot market trade became augmented by their functions as distribution hubs for product that was already in a process of trade via processes of consignment or contract. Second, the scale of buying power that supermarkets now possessed enabled direct procurement channels outside of traditional wholesale markets: supermarkets could deal directly with trading firms, or in some cases, agricultural producers, and bypass wholesale markets.

Along with these organisational changes in the coordination of fresh fruit trade came new conventions - rules governing the conduct of trade - based around private standards. With their emergent market powers, supermarket companies (collectively and individually) authored their own rules about supply requirements. In general, private standards required by supermarkets exceed those written into official rules of trade sanctioned in WTO Agreement, meaning they can act as a de facto non-tariff barrier that restricts who can 
Table 1.4 Major standards in global horticulture

\begin{tabular}{|c|c|c|c|c|}
\hline & \multicolumn{2}{|l|}{ Public } & \multicolumn{2}{|l|}{ Private } \\
\hline & Mandatory & Voluntary & Individual & Collective \\
\hline National & $\begin{array}{l}\text { National } \\
\text { legislation } \\
\text { (pesticide use, } \\
\text { labour regulations, } \\
\text { sanitary } \\
\text { inspections etc.) } \\
\text { U.S. Department } \\
\text { of Agriculture } \\
\text { (USDA) standards }\end{array}$ & $\begin{array}{l}\text { Hazard Analysis } \\
\text { Critical Control } \\
\text { Point (HACCP) } \\
\text { USDA national } \\
\text { organic program }\end{array}$ & $\begin{array}{l}\text { Nature's Choice } \\
\text { (Tesco) } \\
\text { Field-to-Fork (M\&S) } \\
\text { Terre et Saveur } \\
\text { (Casino) } \\
\text { Conad Percorso } \\
\text { Qualita (Italy) } \\
\text { Albert Heijn BV: } \\
\text { AH Excellent } \\
\text { (Netherlands) }\end{array}$ & $\begin{array}{l}\text { British Retail } \\
\text { Consortium (UK) } \\
\text { Assured Foods } \\
\text { Standards (UK) }\end{array}$ \\
\hline Regional & EU Regulations & & $\begin{array}{l}\text { Filieres Qualite } \\
\text { (Carrefour) }\end{array}$ & $\begin{array}{l}\text { EurepGap } \\
\text { Dutch HACCP } \\
\text { Qualitat Sicherhiet } \\
\text { (QS-Belgium, } \\
\text { Holland, Austria) } \\
\text { International Food } \\
\text { Standard (German, } \\
\text { French, Italian) }\end{array}$ \\
\hline International & $\begin{array}{l}\text { World Trade } \\
\text { Organization SPS } \\
\text { Agreement }\end{array}$ & $\begin{array}{l}\text { ISO } 9000 \\
\text { ISO } 22000\end{array}$ & $\begin{array}{l}\text { SQF 1000/2000/3000 } \\
\text { (US) }\end{array}$ & $\begin{array}{l}\text { GlobalGap } \\
\text { Global Food Safety } \\
\text { Initiative } \\
\text { SA } 8000 \\
\text { International } \\
\text { Federation of } \\
\text { Organic Agriculture } \\
\text { Movements } \\
\text { (IFOAM) Standard }\end{array}$ \\
\hline
\end{tabular}

Source: Fernandez-Stark et al. (2011: 9)

participate in trade. A notable and dominant private standard with respect to fresh fruit is the family of GAP (Good Agricultural Practice) standards that owe their genesis to a consortium of European supermarkets seeking to manage the quality requirements of supply. However, as indicated in Table 1.4 , there is a complex interplay of official, corporate and private sector collective standards operating at different sovereign scales.

The emergent, twenty-first century, globalised combination of increased scale and scope of trading and logistics firms on the one hand, and enhanced supermarket buying reach and power on the other, led Reardon et al. to argue that global horticulture was being restructured in accordance with 'four pillars' 
of change: (1) centralised procurement by supermarket retailers; (2) use of specialised wholesalers and logistics firms for supplier selection; (3) listing of 'preferred suppliers' who satisfy downstream actors' demands through contracted arrangements; and (4) development of private standards by supermarkets to manage compliance by upstream suppliers. ${ }^{12}$

The organisational reconfigurations in GPN coordination by these lead firms then gives rise to the second key question posed by the GPN approach, namely, how do they strategically couple with production sites? The role of supermarket and trading companies' downstream buying power and their mechanisms of governance and control via private standards are critically important to this question. Because these lead firms have the capacity to impose these standards as mandatory requirements for participation in GPNs, they have wide-ranging powers to dictate the evolution of economic arrangements in production regions. For this reason, in the terminology of GPN 2.0 it can be suggested that fruit producing regions mainly connect to GPNs through modes of structural coupling, in which large globally footloose buyers use their sourcing freedoms to extract economic benefits from spatially fixed producers. ${ }^{13}$

The controlling influence of large buyers and the role of private standards critically shape the types of producers in fresh fruit growing regions. Production arrangements for fruit cultivation take many forms; however, producers can be classified broadly into three types: smallholders, mid-sized contract farmers, and plantations. Lead firms strategically couple with regional production sites dominated by smallholder, contract farming and plantation landscapes using different mechanisms, and with different effects.

Regional production landscapes dominated by smallholders, in general, pose the greatest challenges for strategic coupling into GPNs. This is on account of the inevitable high transaction costs associated with collecting small volumes of product from large numbers of producers, and the difficulties in assuring certification and quality compliance. Where smallholder production is incorporated into GPNs it tends to require collective interventions in the form of NGO-backed and funded certification systems, and cooperative marketing. ${ }^{14}$ Proof of compliance with private standards tends to require adherence to a certification and audit regime, which is expensive, and therefore has imposed large barriers on small producer participation, unless reparative interventions are made such as subsidising accreditation. ${ }^{15}$ Such arrangements are, however, vulnerable to the withdrawal of NGO support and the flexible entry and exit of smallholders from GPNs as individual households rebalance decisions to grow commercially, grow for own-consumption, or reallocate household labour from farm to non-farm activities. ${ }^{16}$ As a general rule, smallholder participation in GPNs is most efficacious when it is aligned to particular niches such as fair trade, specialist products or credence attributes of product, such as organic agriculture, and this provides a basis for price premiums being allocated 
upstream to smallholder producers. The reality, however, is that for the most part, the development of international supermarket-led GPNs in the fresh fruit sector operates largely in ways that exclude smallholders.

Regional contract farming production landscapes provide organisational mechanisms to address otherwise high coordination costs and certification problems among individual farmers. The general term 'contract farming' encapsulates a wide variety of arrangements that contractually link farmers with a buyer. From the perspective of downstream processing, packing and trading companies, contract farming is a means to exercise control over on-farm activities and practices without becoming directly involved in the ownership and management of land, with its attendant risks and capital costs. It also provides a convenient mechanism to bypass political restrictions relating to land ceilings and foreign ownership of land. Via contract farming, a large downstream (and potentially foreign) company can exercise considerable control over agricultural production systems without any direct ownership stake.

For fresh fruit GPNs, the specifics of contract farming typically involves a coordinating role being played by a packing house or trader directly downstream from the farm sector. Depending on the institutional context, this actor will seek to commit farmers to grow exclusively for them using either legal instruments or financial incentives in terms of operating capital on concessional terms. The agreement often involves seed and chemical supply, agreed arrangements on harvesting and delivery, and incorporation of contracted farmers within an audit regime to ensure compliance and certification of the produced fruit. ${ }^{17}$ Research on contract farming schemes has identified that over time, downstream actors tend to winnow the contract farmers on their books to a smaller number of larger operators. ${ }^{18}$ Successful and/or more compliant contract farmers are rewarded with larger contracts, with the result that agricultural regions can evolve into more homogenous production landscapes involving a smaller number of mid- to large-sized producers.

The third broad type of production landscape in the fresh fruit sector is plantation-based production. These are sites of production dominated by large holdings, which often owe their origins to colonial political systems in which production was organised for export. From economic perspectives, advantages of plantation production derive from the economies of scale in labour, cultivation and marketing. On the flipside, plantation systems in the contemporary world are typically obliged to employ labour in accordance with specified wage schedules and employment practices, and this can lead to higher costs compared to family-based, and highly flexible, smallholder-based systems of production. In the fresh fruit sector, plantations tend to be more common in tree crops than perennial production, because trees represent long-term unmovable fixed capital. 
From a GPN perspective, plantations offer key advantages over other production systems because of their capacity to ensure rigorous compliance with certification regimes. Hence, in sectors such as tea and coffee, plantations exercise some key marketing advantages over other arrangements because of their assurances on the uses of pesticides, compliance with other environmental requirements and uses of labour consistent with international codes of practice.

In summary, existing research into fresh fruit GPNs and their strategic coupling with production landscapes in the global South suggests that the critical roles of standards-compliance and transactional efficiencies generate incentives for lead firms to encourage a concentration of agricultural production into larger-scaled operations, either certified in their own right (such as with plantations) or via modes of organisational coordination (such as contract farming). ${ }^{19}$ However, the extent to which lead firms can orchestrate these outcomes - i.e., restructure production landscapes into ever-larger upstream farming suppliers - depends on their capacity to institute economic, policy and social change to pre-existing geographies. It may be the case in some production landscapes that tightly-held farm systems of smallholders or mid-sized operators constrain consolidation. In other cases, political pressures to maintain support for smallholder populations may limit the powers of lead firms to impose change on production landscapes. With these general points made, attention now turns to the ways these issues are playing out in the fresh fruit production landscapes of mainland Southeast Asia servicing the Chinese market.

\section{CHINA-CENTRIC FRESH FRUIT PRODUCTION NETWORKS IN MAINLAND SOUTHEAST ASIA: ORGANISATIONAL ATTRIBUTES AND REGIONAL DEVELOPMENT IMPLICATIONS}

To date, the topic of China-centric fresh fruit networks in mainland Southeast Asia has received scant research interest. As noted at the outset of this chapter, this research neglect can be hypothesised as being due to its very recent evolution, the practical difficulties in gaining information about the sectors, and the challenges of working across multi-lingual field environments. In a broader sense, the paucity of research on this topic mirrors a wider relative neglect of the role of China as a key actor (if not the key actor) in contemporary global agri-food systems. What is intriguing in the case of China is how the country has rapidly emerged as both a key export source and key import destination within global food trade flows. ${ }^{20}$ Hence, recent Chinese trends simultaneously feed into narratives of 'who will feed China?' and 'China as the farm to the world'. In the case at hand, our investigation considers just one small part of this dynamic - how mainland Southeast Asian production is satisfying Chinese 
demand for fresh fruit - but this remains part of a much larger story of the changing role of China within the global food economy.

Our research comprises seven case studies of fruit producing regions in mainland Southeast Asia, covering five fruit items (dragon fruit, durian, longan, mango, watermelon) in four countries (Laos, Myanmar, Thailand, and Vietnam). Fresh fruit production networks for exports to China cannot be generalised as they are largely influenced by distinctive characteristics of individual fruits as well as economic institutions of individual countries. Although our list of case studies is far from exhaustive, this combination takes into account two crops for each country except for Laos and both perennial and annual crops. Furthermore, case studies of watermelon in three countries (Laos, Myanmar and Vietnam) shed light on how geographical and socio-economic settings have ramifications on the structure of the production network.

In the discussion that follows, we draw upon both the broader insights about this industry established in the previous section and the contributions of case study research reported elsewhere in this volume. From these sources, we divine four key themes in the organisational attributes and regional development implications of Chinese demand for fresh fruit grown in mainland South Asia. These are now discussed successively.

\subsection{Lead Firms and Consumer Channels 'with Chinese Characteristics'}

The existing research discussed in the previous section conceptualises fresh fruit production occurring within buyer-led organisational arrangements in which large international supermarkets act in coordination with powerful transport, logistics and trading firms to execute lead firm governance. These arrangements vary in three important ways when it comes to Southeast Asian fresh fruit production for the Chinese market.

First, the Chinese retail environment for fresh fruit does not conform to the oligopolistic pattern that is dominant in Europe and North America. Although the supermarket sector has grown extremely rapidly in China, from a take-off in the mid-1990s, ${ }^{21}$ it remains less concentrated than in Europe and North America, and as a result it plays a weaker role in the governance of imported fruit value chains. The top four supermarket companies in China control only 27.3 per cent of industry turnover, with the largest company (Sun Art) having a market share of just 8.2 per cent. ${ }^{22}$ By way of comparison, the market share of the four largest supermarket retailers was 44 per cent in the US and 70 per cent in the UK. ${ }^{23}$ A key ramification of this lesser level of concentration is that this sector has not driven change to the organisation of wholesale markets and distribution centres comparable to what has occurred in Europe and North 
America. The infrastructures of food logistics and distribution in China remain more pluralistic in character than the more centralised model in the West.

However, this is not to say that change is not occurring in the way that fresh fruit is sold to Chinese consumers. The second key point we make is that China appears at the vanguard of emergent trends of e-tailing and e-commerce in the fresh fruit sector. As argued by Yang (this volume), affluent urban markets in China are in the midst of dramatic change as the younger generation expresses dramatically different priorities and preferences with respect to food purchasing. Yang argues that we are seeing a complex, inchoate integration of various platforms including traditional 'bricks and mortar' retail, online purchasing, and a new category of hybrid 'convenience stores' operating simultaneously in the digital and physical worlds - what one of her informants labels as giving a 'phygital' experience to customers. At present, this is typified by Hema Fresh, a 'bricks and mortar' chain of food stores operated by the online giant Alibaba. Yang cites industry sources that indicate that e-commerce channels account for between 15 and 30 per cent of food purchasing market share in China and are growing rapidly.

At this point in time there is no comprehensive knowledge about how these new e-commerce platforms are sourcing their product. Research on exports of Thai longan to China undertaken as part of the contribution by Kmonpetch and Jitpong (this volume) indicates that in this case at least, Alibaba sources directly from packing centres in Thailand. Longan fruit is packed and labelled according to Alibaba's requirement and shipped direct to China. In other cases, it would be imagined that these companies source product via large wholesale markets in China, such as the Jiangnan Market in Guangzhou, China's largest. As reported in fieldwork by Yang (this volume), the Jiangnan operations are increasingly making use of B2B apps and traceability technology connected in some cases to border crossings with mainland Southeast Asia (such as Pingxiang on the China-Vietnam border).

Third, the lesser role of supermarkets and large transport and logistics companies as lead firms in servicing the Chinese consumer with Southeast Asian fresh fruits is also a product of the importance of the land border in Southeast Asia-China trade. Consistent with the analysis of Comtrade data presented earlier in this chapter, it is very difficult to ascertain the volume of trade that crosses into China by land from Southeast Asia. What is known is that trade volumes have increased dramatically in recent years in the five official land border crossings that link mainland Southeast Asia to China: the DongxingMóng Cái, Pingxiang-Lang Son, and Hekou-Lao Cai crossings connecting China with Vietnam, the Mohan-Boten crossing connecting China with Laos, and the Ruili-Muse crossing connecting China with Myanmar (Figure 1.2). Large-scale transport and logistics firms are less dominant in these land border crossings than is the case in airports and seaports, where scale and 
sophistication of operations play a much more important role. As a result, the considerable proportion of mainland Southeast Asian fresh fruit entering China by land does so through diverse trucking and distribution arrangements, and the companies involved in these activities play more functionally limited governance roles in these production networks.

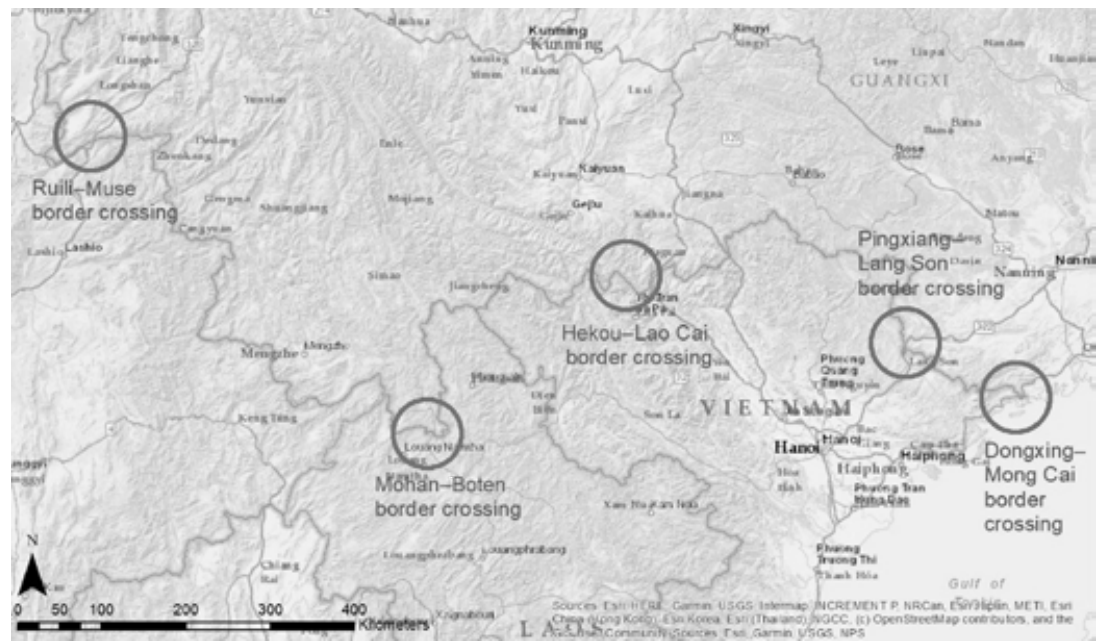

Source: Compiled by the author.

Figure 1.2 Land border crossings between mainland Southeast Asia and China

\subsection{A Haphazard Ecology of Conventions}

As discussed with respect to the fresh fruit trade to Europe and North America, and illustrated in Table 1.4, a complex web of official, corporate and collective private standards has dictated the conduct of this trade. And as further discussed above, this ecology of conventions has had concrete implications on the evolution of producer entities within fruit growing regions. The financial and organisational imposts associated with standards compliance have shaped the economics of GPN inclusion among farming communities.

The export of fresh fruit from mainland Southeast Asia to China is organised through a quite different ecology of conventions. This is constituted by an emerging, more rigorous role of the Chinese state as an authority within the official trade of fresh fruit, a minimal presence of corporate standards, a variable need for recognition of collective private standards, and a widespread flow of trade that bypasses all standards-setting regulatory regimes altogether. 
Starting with official standards, recent years have witnessed a more muscular approach by the government of China to exercise its influence in ensuring the fresh fruit phytosanitary certificate imported into China meets approved standards. The Chinese government has centralised administration of this area and created clearer lines of departmental authority via transferring key responsibilities to the General Administration of the Customs (GAC). Over time, the GAC actively expanded its remit, mandating additional certification on imported fresh fruit. The politics behind this agenda derive from public disquiet over recent food scares in China. ${ }^{24}$ In 2013, relevant agencies involved in food safety were restructured and in 2015 new national food safety legislation was implemented. Then in 2018, the GAC took on wider responsibilities as the relevant authority for food imports.

The stronger presence of the government of China in dictating standards for fresh fruit imports from mainland China, however, is expressed unevenly. Case studies reported in this volume provide contrasting examples of compliance requirements and adherence. For example, whereas Kmonpetch and Jitpong (this volume) report that all longan exports from Thailand to China are required to have a certificate demonstrating fumigation prior to export, Kubo and Wah Wah Htun (this volume) report that although mango exports from Myanmar require a phytosanitary certificate, this is undertaken only on the basis of a live insect inspection on a small sample of fruit, and in any case China Customs at the Ruili border accepts fruits without phytosanitary certificates. Therefore, although the government of China is enacting more stringent official requirements for fresh fruit imports, this agenda remains a work-in-process that is uneven between countries and commodities.

In other parts of the word, private standards play a role in ensuring adherence to product quality requirements amidst inconsistencies in state-led certification. In China, however, private standards are rare. In the words of one observer: 'few food products are privately certified [in China], and where private labels are present, consumers distrust them because they are perceived to be counterfeit or received in return for financial inducement rather than a guarantee of food quality/safety'. ${ }^{25}$ Collective private standards, such as GAP, are also on the margins of this issue. During the past decade, governments in mainland Southeast Asian countries have sought to upgrade their export horticultural industries by rolling out subsidised GAP certification. This has facilitated many producers in these countries to export to key northern markets such as Europe and North America. However, while many of the fresh fruit exports from mainland Southeast Asia to China are GAP-certified, in the example of dragon fruit exports from Vietnam, Sakata (this volume) argues that such certification has not had a meaningful effect in securing market access or enabling higher prices to producers. 
Also relevant to this debate is the sophistication of customs infrastructure at land border crossings. Because of the role of 'permit lists' (see below) in providing country-specific allowances and prohibitions on trade commodity-by-commodity, there are strong incentives for mis-certification of product origins. This is the case, for example, in fresh fruit grown in Thailand but trans-shipped across Vietnam that is labelled 'Product of Vietnam' to circumvent rules or levies. Because of lax reporting infrastructure at border crossings, certification requirements may be formally met based on fraudulent claims. Finally, it needs noting that the land border between China and mainland Southeast Asia is porous at several points, and there is an unofficial, largely unregulated flow of local trade, including fresh fruit, between countries. The scale and characteristics of this trade are unknown and add problematically to the overall picture of a haphazard ecology of conventions in this production network.

Taken together, these aspects of how standards act (or not) as conventions of the trade of fresh fruits from mainland Southeast Asia to China have two clear implications for industry arrangements. First, they mitigate specialisation between different classes of producers. This argument is similarly made by Neilson and Wang with respect to the Chinese coffee sector, who argue that the emergence of China as a major importer of coffee is emblematic of a 'departure from post-1989 global trends, whereby the GVC for coffee has been deregulated and then effectively re-regulated through private sector governance, including the introduction of sustainability standards' ${ }^{26}$ In China, the relative absence of private standards means that markets are less fractured into specialist niches. Grading of product certainly occurs, but in the products assessed in later chapters of this volume it seems to be only loosely attached to price distinctions both at farm gate and retailer levels. Second, the lesser role of standards-setting by private actors provides fewer incentives for downstream actors to take active involvement in the monitoring of upstream production activities. This is unlike the instance of tropical products cultivated for export to Europe and North America, which are tightly connected to traceability and audit technologies from downstream buyers. As a result, a larger proportion of fresh fruit imported into China is exchanged at border markets under spot market transactions in which product origins are understood only loosely. For example, as revealed in research by Kubo (this volume), the export of watermelons from Myanmar to China includes the congregation of buyers at a border auction each morning during the harvest season, with exchange occurring largely on a visual assessment of quality. 


\subsection{An Economic Geography of Specialist Clusters of Fresh Fruit Cultivation}

A notable characteristic of China-centric fresh fruit production in mainland Southeast Asia is its spatial form as a series of specialist production clusters. Because of its dependence on natural systems (soil, water, climate), the economic geography of horticultural industries is inevitably closely associated with specific, sometimes small, specialist areas of production. However, in the case of fresh fruit grown for the Chinese market, a set of institutional factors further act to generate clusters of production.

The first of these relates to the political rules of trade. China regulates this land border trade through a 'permissible fruit import list' from China Customs, which took over responsibilities from the General Administration of Quality Inspection, Supervision and Quarantine (AQSIQ) in 2018. The permit list of allowable fruits to trade is highly specific to individual countries. As indicated by Yang (this volume), as of April 2019 permissible fresh fruits to be imported from each of the four mainland Southeast Asian countries of interest to this chapter were:

- Laos (banana, watermelon)

- Myanmar (longan, litchi, mangosteen, mango, rambutan, watermelon, other melon, Indian jujube)

- Thailand (tamarind, sugarapple, papaya, carambola, guava, rambutan, rose apple, jackfruit, long kong, pineapple, sapodilla, banana, passion fruit, coconut, longan, durian, mango, litchi, mangosteen, mandarin orange, orange, pomelo)

- Vietnam (mango, longan, banana, litchi, watermelon, rambutan, jackfruit, pitaya [dragon fruit], mangosteen)

The existence of this list means that certain fruits can be exported to China only from permitted countries, and hence this acts to organise the geography of production according to logics of national borders. For instance, the fact that durian can be exported to China from Thailand but not other Southeast Asian countries encouraged this industry to be clustered in southeast Thailand adjacent to seaports where the product can be transported to ports in the Pearl River Delta.

The requirement to maintain freshness in fruit exported to China additionally means that production sites need ready access to transport and logistics infrastructure, including packing houses for some products. As a result, there tends to be a clustering of cultivation close to these facilities, and an ensuing high level of dependence in local economies on continuing access to the Chinese market. All the case studies in this volume describe production clusters that 
owe their existence to exporting to China. Hence, for Vietnam, China was the destination of 87 per cent of banana exports, 91 per cent of dragon fruit exports (Sakata, this volume) and 100 per cent of watermelon exports (Takanashi, this volume). In Myanmar, 99 per cent of mango exports (Kubo and Wah Wah Htun, this volume) and 100 per cent of watermelon exports (Kubo, this volume) were destined for China. Nattapon and Wannarat Tantrakoonsab (this volume) report that in 2018, 59 per cent of durians exported from Thailand were destined for China and Hong Kong; however, a further 38 per cent were recorded as being exported to Vietnam, which the authors strongly suspect were in transit to China. Bannalath and Nolintha (this volume) report that the relatively small watermelon production complex in Luangnamtha Province of Laos is also overwhelmingly dependent on exports to China; however, because of the absence of official data (much trade occurs informally across the border), this is impossible to authenticate.

These fresh fruit clusters additionally rely on a ready supply of agricultural labour. Fresh fruit production tends to be heavily labour-intensive, especially in peak harvest seasons. Meeting these labour requirements can involve the need to mobilise non-local labour, sometimes across international borders. The most striking example of this is in the Thai longan sector in Chantaburi Province, where guest worker agreements with Cambodia facilitate a flow of labour to meet seasonal harvest needs. However, these themes are apparent in other sites as well, for example in northern Myanmar where the seasonal labour requirements of the watermelons sector encourage flows of labour from other rural regions in the country.

\subsection{Increased Chinese Presence in Fruit Growing Regions}

In the past few years there has been a notable increase in the participation of Chinese traders and entrepreneurs across the different study sites documented by this research. These developments represent a very interesting evolution in the organisation of production networks at production sites, because at face value they appear to run counter to other observations made in this chapter.

The discussion above has drawn a series of contrasting points between the evolution of fresh fruit networks in mainland Southeast Asia serving the China market, and industry trends dominant in other settings. The broad argument has been that supermarkets and transport/logistics companies play a less dominant role as lead firms for this trade and that, partially as a result, fresh fruit producers selling to the Chinese market are less encumbered with the need to comply with a stringent standards regime. Consequently, there are fewer economic incentives, in terms of the logic of transaction cost economics, for downstream actors to robustly intervene in upstream production. 
The fact that our empirical research has identified an increased Chinese presence in production sites, therefore, cannot be explained within the logics of GPN organisation and coordination alone. In the discussion that follows, we firstly outline evidence about the increased Chinese presence in production sites, and then seek to identify explanations for these phenomena.

Five of our seven case studies of production sites in mainland Southeast Asia reported an increasing Chinese presence in production areas. Sakata (this volume) reports that in the Vietnamese dragon fruit sector, a recent development has been for Vietnamese-owned packing houses to be rented out to Chinese trading firms. His research emphasises the 'subtle touch' of this investment - Chinese entrants are not involved in farm-level production in any way, do not establish contracts with farmers, and do not purchase or build new packing house facilities. Rather, they are increasingly renting out existing facilities with a view to controlling the flow of product into packing houses and its onwards distribution to the Chinese border. Kubo's examination of Myanmar watermelon production (this volume) outlines an extensive array of Chinese participation in this sector, which seems to be expanding over time. ${ }^{27}$ This includes approximately half of all watermelon cultivation occurring on farms leased/owned ${ }^{28}$ by Chinese interests, and a large participation of Chinese brokers coordinating downstream sales and distribution. The Myanmar mango sector studied by Kubo and Wah Wah Htun (this volume) does not have direct Chinese participation in cultivation - likely the result of mangoes being tree crops in orchards with clearer land titling status; however, Chinese brokers and traders are key and growing participants in the border trade. In Thailand, Tantrakoonsab and Tantrakoonsab's study of durian exports to China (this volume) reveals a clear trend of increasing participation by Chinese entrepreneurs. These actors have purchased and constructed new packing houses, marginalising Thai businesses from this trade. A very similar narrative is revealed in the study of Thai longan exports by Kmonpetch and Jitpong (this volume), where large Chinese companies have invested heavily in packing house facilities and purchase longan directly from Thai-owned orchards.

The two case studies that did not identify an increasing Chinese presence in production areas are Takanashi's study (this volume) of Vietnamese watermelon production and Bannalath and Nolintha's study (this volume) of watermelon production in Luangnamtha Province, Laos. In the latter case, the trade is small and largely informal, so it is not surprising it has apparently failed to attract upstream involvement by Chinese interests. Takanashi's results are superficially more difficult to reconcile but can be explained by comparing it to the Myanmar case studied by Kubo, discussed above. First, because watermelons do not require packing houses, this node in the production network is removed. Second, the land titling and regulatory system is more sophisticated 
in Vietnam compared to Myanmar and there are narrower opportunities for dubiously sanctioned investments by Chinese interests.

How should the increased presence of Chinese interests in the majority (five of our seven) of the case studies from mainland Southeast Asia be understood? As discussed above, GPN theory alone does not seem to provide a clear answer, as the governance arrangements for this trade do not seem to demand heightened oversight by downstream actors to ensure standards are met. Rather, the supposition we pursue here is that these investments reflect an articulation of the firm-specific competitive advantages of Chinese traders and brokers. These entities generate their competitive advantage from their business-personal networks. Their Chinese ethnicity and language provide a cultural glue that facilitates the exchange of product downstream to buyers at the border, or within China itself. Hence, they represent an extension of the Chinese business community into host countries. As noted in the previous section, production sites tend to be organised as specialist clusters oriented almost wholly to the Chinese market. In these geographical contexts, it then follows that Chinese traders and brokers are well-positioned to enter these locations and control key nodes for production coordination and distribution.

Following from this, these activities may not represent upstream investment by existing firms in these sectors. In some cases (Myanmar watermelon production is an example) there is some evidence that Chinese firms expanded from cultivation into broking/trading. However, in the Vietnamese and Thai cases, firms that are operating packing houses seem to be not always organisationally related to upstream or downstream entities. Their presence represents entrepreneurism - identifying an opportunity in the market - rather than calculated upstream investment to achieve the benefits of more integrated network coordination.

Finally, the issue of increased Chinese participation in production regions raises issues of local value-capture. If Chinese interests are dislodging local interests from these nodes in the network, and if their profits from these activities are repatriated elsewhere (for instance, back to China), their presence would seem to detract from regional value-capture. At the same time, of course, their investment and access to the China market may stimulate increased expansion of these sectors. Therefore, it remains unclear how increased Chinese participation in mainland Southeast Asian fruit producing regions will impact upon their future growth trajectories, but this is certainly a topic worthy of future research consideration. 


\section{CONCLUSION}

This chapter has shone a light into the currently under-researched topic of the fresh fruit trade between four mainland Southeast Asian countries (Thailand, Vietnam, Myanmar and Laos) and China. This is an important agri-food system from a global perspective. China is a vital actor in the world's food economy, exercising its weight both as an exporter and importer. Through the course of the twenty-first century, if present trends continue, the global food system will become increasingly China-centric. Understanding the evolution of the global production networks servicing this market is, therefore, a key research agenda for agri-food researchers worldwide.

Fresh fruit is a growing component of the Chinese diet, symptomatic of the rapidly expanding middle-class consumer base in the country. Fruit production sites in adjacent nations in mainland Southeast Asia have been developed or reoriented to service this trade. This production is transported to China by air, sea and land, with the latter mode having particular significance in terms of shaping the organisational logics of trade. It has also acted to encourage obfuscation of statistics measuring the trade.

To date, the trade of fresh fruit from mainland Southeast Asia to China has exhibited characteristics that present some significant differences between those found in other export-oriented fresh fruit industries. These include a lesser role for private and collective standards as conventions governing this trade, and differences in the nature of the lead firms in this trade. Compared to Europe and North America, international supermarket chains and transport/ logistics firms play smaller roles in network governance. In the mainland Southeast Asia-China trade, governance modes have developed with a high degree of coordination around mid-chain agents and brokers.

At the same time, this trade is undergoing considerable transformation presently, as a result both of new consumer platforms, especially relating to e-commerce, and a stronger presence of the Chinese state in establishing food safety standards. Within production sites, there is a visibly greater presence of Chinese interests, and the future role that these actors play in these GPNs will have substantial ramifications for value-capture trajectories within regions.

The remainder of this volume discusses these issues in their specifics, using empirical research from each of the four mainland Southeast Asian countries under review here, and in one case (Yang, this volume) from the Chinese side. This volume represents the first comprehensive effort to apply a global production network analysis to this sector, and although adding key original insights to the topic it inevitably represents just the starting point for a fuller analysis of this subject. 


\section{NOTES}

1. Fresh fruit is defined as HS codes 0803 to 0810 inclusive. 'HS' stands for the Harmonized Commodity Description and Coding System, used by the UN Comtrade database.

2. See, by contrast, Zhan et al. (2018).

3. Henderson et al. (2002) and Coe et al. (2004).

4. Coe and Yeung (2015: 32).

5. Coe and Yeung (2015).

6. Coe and Yeung (2015: 168). Note that this is not always positive. GPN theorists also discuss 'the dark side of strategic coupling' when lead firms utilise regional assets in exploitative ways.

7. Van den Broek and Maertens (2016).

8. Weis (2004).

9. Barling and Lang (2005).

10. Fold and Pritchard (2005).

11. Fernandez-Stark et al. (2011: 1).

12. Reardon et al. (2003).

13. Coe and Yeung (2015: 157 and 187).

14. Franz et al. (2014).

15. Vorley et al. (2007) and Neilson and Pritchard (2007).

16. Vicol et al. (2018).

17. Ouma (2012).

18. Vicol (2019).

19. Van den Broek et al. (2017).

20. Zhan et al (2018).

21. Hu et al. (2004).

22. The top ten companies, in ascending order are: Spar 1.6\%; WuMart 1.8\%; WSL 2.0\%; Bailian 2.6\%; Carrefour 3.1\%; Yonghui 3.7\%; Walmart 5.7\%; Vanguard 6.5\%; RT-Mart 6.9\%; Sun Art 8.2\% (China Daily, 2018).

23. USDA-ERS (2018) and USDA-FAS (2018).

24. Pritchard and Chan (2016).

25. Zhang et al. (2016: 270).

26. Neilson and Wang (2019: 446).

27. Also see: Kubo et al. (2019).

28. Actual land ownership status is difficult to verify because of cloaking techniques used to circumvent restrictions on foreign ownership of land in Myanmar.

\section{REFERENCES}

Barling, D. and T. Lang (2005). Trading on health: Cross-continental production and consumption tensions and the governance of international food standards. In Fold, N. and B. Pritchard (eds) (2005). Cross-Continental Agro-Food Chains: Structures, Actors and Dynamics in the Global Food System. London: Routledge, pp. 55-67.

China Daily (2018). Top ten retailers with largest market share in China, 20 September 2018. Accessed 12 June 2019 at www.chinadaily.com.cn/a/201809/20/WS5ba2 d03fa310c4cc775e7272_1.html

Coe, N. and H. W. C. Yeung (2015). Global Production Networks. Oxford: Oxford University Press. 
Coe, N. M., M. Hess, H. W. C. Yeung, P. Dicken and J. Henderson (2004). 'Globalizing' regional development: A global production networks perspective. Transactions of the Institute of British Geographers 29(4), 468-484.

Fernandez-Stark, K., P. Bamber and G. Gereffi (2011). The Fruit and Vegetables Global Value Chain. Center for Globalization, Governance and Competitiveness, Duke University.

Fold, N. and B. Pritchard (eds), Cross-Continental Agro-Food Chains: Structures, Actors and Dynamics in the Global Food System. London: Routledge.

Franz, M., M. Felix and A. Trebbin (2014). Framing smallholder inclusion in global value chains - case studies from India and West Africa. Geographica Helvetica 69(4), 239-247.

Henderson, J., P. Dicken, M. Hess, N. Coe and H. W. C. Yeung (2002). Global production networks and the analysis of economic development. Review of International Political Economy 9(3), 436-464.

Hu, D., T. Reardon, S. Rozelle, P. Timmer and H. Wang (2004). The emergence of supermarkets with Chinese characteristics: Challenges and opportunities for China's agricultural development. Development Policy Review 22(5), 557-586.

Kubo, K., B. Pritchard and A. S. Phyo (2019). How is Chinese fresh fruit demand remaking agrarian regions in mainland Southeast Asia? Lessons from the Myanmar melon frontier. Unpublished manuscript.

Neilson, J. and B. Pritchard (2007). Green coffee? The contradictions of global sustainability initiatives from the Indian perspective. Development Policy Review 25(3), 311-331.

Neilson, J. and J. Z. Wang (2019). China and the changing economic geography of coffee value chains. Singapore Journal of Tropical Geography 40(3), 429-451.

Ouma, S. (2012). Creating and maintaining global connections: Agro-business and the precarious making of fresh-cut markets. Journal of Development Studies 48(3), 322-334.

Pritchard, B. and Y. W. Chan (2016). The new consumer politics of food in East Asia: Food safety, food scares, and 'eating right'. Asia Pacific Viewpoint 57(3), 297-300.

Reardon, T., C. P. Timmer, C. B. Barrett and J. Berdegué (2003). The rise of supermarkets in Africa, Asia, and Latin America. American Journal of Agricultural Economics 85(5), 1140-1146.

UN Comtrade (2019). UN Comtrade database. Accessed various dates at https:// comtrade.un.org/data

United States Department of Agriculture Economic Research Service (USDA-ERS) (2018). Retail trends. Accessed 12 June 2019 at https://www.ers.usda.gov/topics/ food-markets-prices/retailing-wholesaling/retail-trends/

United States Department of Agriculture Foreign Agricultural Service (USDA-FAS) (2018). United Kingdom - retail foods. Accessed 12 June 2019 at https://gain .fas.usda.gov/Recent $\% 20$ GAIN\%20Publications/Retail\%20Foods_London_United \%20Kingdom_6-15-2018.pdf

Van den Broeck, G. and M. Maertens (2016). Horticultural exports and food security in developing countries. Global Food Security 10, 11-20.

Van den Broeck, G., J. Swinnen and M. Maertens (2017). Global value chains, large-scale farming, and poverty: Long-term effects in Senegal. Food Policy 66, 97-107.

Vicol, M. (2019). Potatoes, petty commodity producers and livelihoods: Contract farming and agrarian change in Maharashtra, India. Journal of Agrarian Change 19(1), 135-161. 
Vicol, M., N. Fold, B. Pritchard and J. Neilson (2018). Global production networks, regional development trajectories and smallholder livelihoods in the Global South. Journal of Economic Geography 19(4), 973-993.

Vorley, B., A. Fearne and D. Ray (2007). Regoverning Markets: A Place for Small-Scale Producers in Modern Agrifood Chains? London: Routledge.

Weis, T. (2004). Restructuring and redundancy: The impacts and illogic of neoliberal agricultural reforms in Jamaica. Journal of Agrarian Change 4(4), 461-491.

Zhan, S., H. Zhang and D. He (2018). China's flexible overseas food strategy: Food trade and agricultural investment between Southeast Asia and China in 1990-2015. Globalizations 15(5), 702-721.

Zhang, L., Y. Xu, P. Oosterveer and A. P. J. Mol (2016). Consumer trust in different food provisioning schemes: Evidence from Beijing, China. Journal of Cleaner Production 134(A), 269-279. 